PREHOSPITAL CARE

\title{
Securing the prehospital airway: a comparison of laryngeal mask insertion and endotracheal intubation by UK paramedics
}

\author{
C D Deakin, R Peters, P Tomlinson, M Cassidy
}

See end of article for authors' affiliations

Correspondence to: $\operatorname{Dr} C$ D Deakin, Hampshire Ambulance Service NHS Trust, Highcroft, Romsey Road, Winchester SO22 5DH, UK; charlesdeakin@ doctors.org.uk

Accepted for publication 30 July 2004
Objectives: The recent introduction of a disposable laryngeal mask airway has provided paramedics with an alternative to endotracheal intubation. Time taken to secure the airway with each device was compared in patients undergoing elective surgery.

Methods: Patients undergoing general anaesthesia were studied. Paramedics trained in laryngeal mask use and endotracheal intubation participated in the study. A Portex disposable laryngeal mask was inserted and removed, followed by a Portex endotracheal tube. Time taken from beginning of the procedure to ventilation of the patient was recorded.

Results: Laryngeal mask insertion and endotracheal intubation was attempted on 52 patients. Median age was 63.5 years (range 39-83). Laryngeal mask insertion was successful in $88.5 \%$ (46 of 52) patients; endotracheal intubation was successful in $71.2 \%$ (37 of 52) patients (after no more than two attempts), $p=0.049$. Intubation success was related to laryngoscopic view $187.5 \%$ grade $1,56.3 \%$ grade $2,0.0 \%$ grade 3. $p<0.0001)$. When laryngeal mask/endotracheal tube insertion were both successful $(n=35$ of 52), there was no significant difference in median time to secure the airway (laryngeal mask 47.0 seconds (range 24-126) compared with endotracheal tube 52.0 seconds (range 27-148) $p=0.22$ ). Laryngeal mask insertion was successful in $80.0 \%$ (12 of 15) patients in whom endotracheal intubation had failed. Conclusions: Even under optimal conditions, 30\% of attempts at intubation by paramedics were unsuccessful. A disposable laryngeal mask has a higher success rate in securing the airway and overall, secures the airway more reliably than endotracheal intubation.
$\mathrm{P}$ rehospital airway management is one of the most challenging prehospital tasks in the management of patients with major trauma. Paramedics in the UK are taught basic airway management as technicians and progress to learn the skills of endotracheal intubation over an eight week course, entailing the practical intubation of at least 25 patients in a controlled hospital environment. Subsequently, the average paramedic attempts endotracheal intubation on about seven patients per annum, which is relatively few for a technique where skills fade fast. Without the use of sedative and neuromuscular pharmacological agents, endotracheal intubation is only possible on severely obtunded patients. Success rates in these circumstances are variable, but generally poor, with success rates below $75 \%$ being regularly reported. ${ }^{1-6}$ Even when successful, the fact that the patient is obtunded sufficiently to tolerate endotracheal intubation without drugs is reflected in the eventual outcome, which is invariably poor, both for trauma ${ }^{7}$ and primary cardiac arrest. $^{89}$ Concerns have also been expressed that prehospital endotracheal intubation may actually be contributing to morbidity and mortality for reasons such as hypoxaemia during intubation itself, unrecognised oesophageal intubation, and mainstem intubation. ${ }^{10}$ These complications may have contributed to conclusions of several recent randomised studies that reported worse outcomes after endotracheal intubation when compared with basic airway management. ${ }^{6}{ }^{10-12}$

The laryngeal mask airway is now well established as an alternative airway to endotracheal intubation for elective surgical procedures. The Joint Royal College Ambulance Liaison Committee guidelines that set the standards for UK paramedic practice have sanctioned the use of this device as an alternative prehospital airway adjunct. ${ }^{13}$ Introduction of the laryngeal mask into paramedic practice has been comparatively slow, with only $23 \%$ of ambulance trusts stocking the device in 2003. Although the laryngeal mask provides less protection of the airway from gastric aspiration than the endotracheal tube, its use during cardiac arrest has shown that it does provide good protection from aspiration of gastric contents. ${ }^{14}$ In major trauma, aspiration of blood from nasopharyngeal trauma is much more common than gastric contents $^{15}$ and the laryngeal mask has also been shown to protect from ingress of blood originating from above the cuff. ${ }^{16}$ Its insertion is an easier skill to learn than endotracheal intubation, can be taught successfully on manikins, and is a superior method than bag-valve-mask in delivering ventilation; delivering better ventilation than bag-valve-mask and reducing the risk of aspiration compared with bag-valvemask. Success rates of insertion are generally $>95 \%{ }^{17}{ }^{18}$ and there is evidence that they may avoid some of the morbidity seen with endotracheal intubation. ${ }^{12}$

With the growing unease of prehospital endotracheal intubation and difficulties with obtaining sufficient hospital based training in the technique, the laryngeal mask is gaining in popularity. The occasional case report of prehospital use $\mathrm{e}^{19-21}$ has been superseded by several large studies attesting to its effectiveness in delivering ventilation in even the most challenging of prehospital environments. ${ }^{22-24}$ With the introduction of disposable laryngeal masks by several manufacturers, an important barrier in terms of cost has been removed and the use of the laryngeal mask by UK paramedics is becoming common practice. An additional concern with current prehospital intubation practice is the risk of cross infection through use of reusable laryngoscope blades; a situation exacerbated by the limited cleaning, sterilising, and quality control systems present within many UK ambulance 
trusts. The disposable laryngeal mask avoids this cross infection risk, particularly in relation to prion transmission. ${ }^{25}$

Although there are numerous manikin studies comparing laryngeal mask insertion or endotracheal intubation, there is a need for more quantitative clinical studies comparing the two devices. We therefore designed a study to compare the time taken to secure the airway using laryngeal mask insertion and endotracheal intubation in patients undergoing elective surgical procedures to assess whether any difference exists between the two devices. Most paramedic attempts at endotracheal intubation in the UK are for non-trauma related causes where the cervical spine is not at risk. We therefore used a similar scenario for the study patients.

\section{METHODS}

After ethics committee approval and informed written consent, we sequentially recruited patients undergoing general anaesthesia for elective cardiac surgery. Routine medication was continued until the morning of surgery. Patients received lorazepam, $1-2 \mathrm{mg}$ orally two hours preoperatively, followed by morphine $5-10 \mathrm{mg}$ and maxolon $10 \mathrm{mg}$ intramuscularly one hour before surgery. Radial artery and peripheral venous catheters were inserted under local anaesthesia. Anaesthesia was induced using midazolam $0.02-0.05 \mathrm{mg} / \mathrm{kg}$ or propofol $2-3 \mathrm{mg} / \mathrm{kg}$, fentanyl $10-15 \mu \mathrm{g} /$ $\mathrm{kg}$, and pancuronium $0.1 \mathrm{mg} / \mathrm{kg}$. After administration of induction agents, the patient was ventilated manually for three minutes using $100 \%$ oxygen delivered through a Mapleson E circuit and face mask.

A single use Portex Soft Seal laryngeal mask (LM) (Smiths Medical, Hythe, UK) and a Portex endotracheal tube were lubricated and prepared for use, together with suction and a laryngoscope. The paramedic performing the airway management was given no assistance other than cricoid pressure applied to the patient by a trained assistant. The laryngeal mask airway was inserted first, the cuff inflated, and the patient ventilated manually using $100 \%$ oxygen. Once the patient was reventilated, the LM was removed and endotracheal intubation was attempted. No more than two attempts were permitted for insertion of each device, after which the procedure was deemed to have failed. The time taken to secure the airway with both devices was the time from the paramedic being asked to begin the procedure to the confirmation of end tidal carbon dioxide by sidestream capnography during manual ventilation. All studies were supervised by a consultant anaesthetist. After insertion of the endotracheal tube, the study was concluded and anaesthetic preparation of the patient continued as normal. In patients where paramedic endotracheal intubation failed, the procedure was completed by the supervising consultant anaesthetist.

Paramedics undertaking the study had all been trained in the use of the LM airway according to JRCALC guidelines and were clinically at a level of competence to attempt endotracheal intubation and LM insertion in the prehospital setting.

Table 1 Success rates and times to achieve laryngeal mask insertion and endotracheal intubation

\begin{tabular}{lllll}
\hline & $\begin{array}{l}\text { \% Success } \\
(\mathbf{n}=)\end{array}$ & $\begin{array}{l}\text { Median time } \\
\text { to insertion } \\
\text { (seconds) }\end{array}$ & $\begin{array}{l}\text { 95\% Confidence } \\
\text { intervals (seconds) }\end{array}$ \\
\hline $\begin{array}{l}\text { Laryngeal } \\
\text { mask }\end{array}$ & $\begin{array}{l}88.5 \\
(46 \text { of } 52)\end{array}$ & 47.0 & 41.0 & 58.0 \\
$\begin{array}{l}\text { Endotracheal } \\
\text { tube }\end{array}$ & $\begin{array}{l}71.2 \\
\text { (37 of 52) }\end{array}$ & 52.0 & 50.0 & 57.0 \\
\hline
\end{tabular}

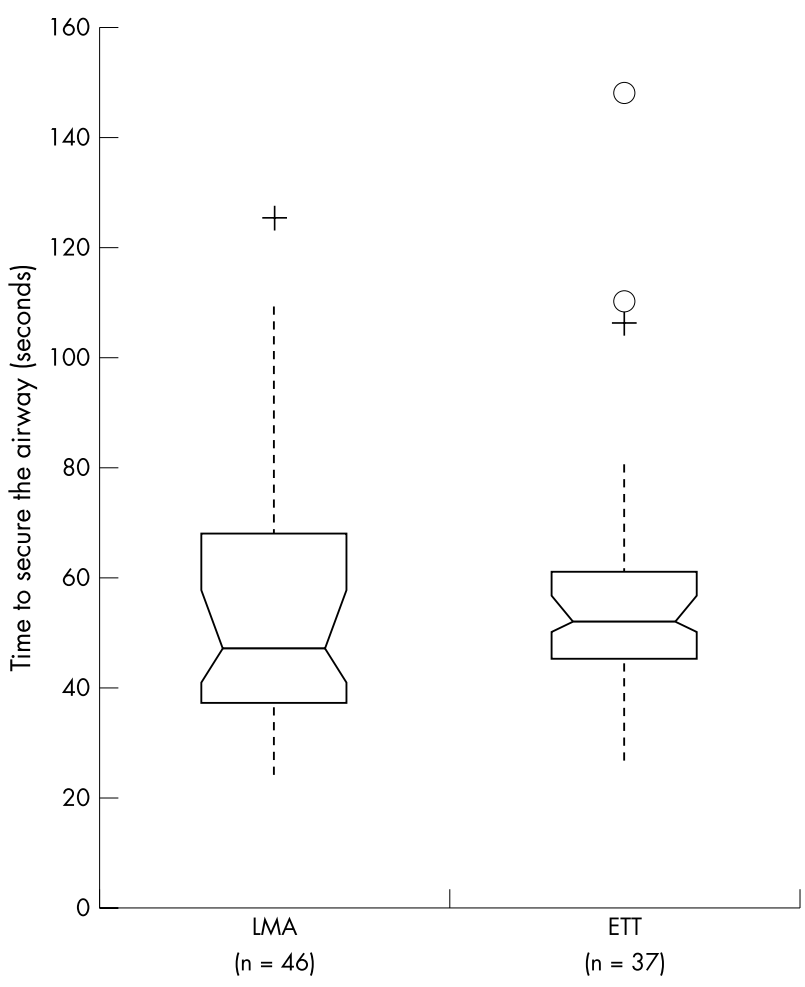

Figure 1 Box and whisker plot showing time to successfully secure the airway using a laryngeal mask (LM) and endotracheal tube (ETT). (Plot shows median, lower, and upper quartiles and confidence interval around the median (shoulders). Dotted line connects the nearest observations within 1.5 IQRs (interquartile ranges) of the lower and upper quartiles. " + " Represents observations more than 1.5 IQRs and "O" 3.0 IQRs from the quartiles).

A previous study has reported a mean (SD) time of 40 seconds ( 1.9 seconds) for LM insertion by paramedics. ${ }^{26}$ Assuming that a mean time of 60 seconds for endotracheal intubation would be a clinically relevant difference, power calculations showed that 50 paired samples will give the study a power $>0.90$ taking significance as $p \leqslant 0.05$.

Statistical analysis was performed using the "Analyse-it" add-in for Microsoft Excel 2000 (Analyse-it Software, PO Box 77, Leeds LS12 5XA, UK). Descriptive data are presented using non-parametric analysis. Fisher's exact test $(2 \times 2$ table $)$ was used to compare success rates of LM and endotracheal tube insertion. Time taken to secure the airway was compared using a two tailed paired $t$ test. Significance was taken as $\mathrm{p} \leqslant 0.05$.

\section{RESULTS}

LM insertion and endotracheal intubation was attempted on all 52 patients who consented to partake in the study. Twenty four paramedics studied two patients, and the remaining four studied one patient each. Twenty one of the paramedics were attending theatres for refresher training; the remaining seven had just completed their paramedic training and had placed at least 10 LMs under supervision in theatre. All paramedics were at, or had reached, the stage where they had or were able to place LMs unsupervised in the prehospital setting.

Median patient age was 63.5 years (range 39-83). LM insertion was successful in $88.5 \%$ (46 of 52) patients; endotracheal intubation was successful in $71.2 \%$ ( 37 of 52 ) patients (after no more than two attempts). Difference between proportions $=0.17,95 \%$ confidence intervals from 0.022 to $0.32, \mathrm{p}=0.049$. 


\begin{tabular}{|c|c|c|c|c|c|}
\hline $\begin{array}{l}\text { Cormack and } \\
\text { Lehane view }\end{array}$ & Grade I & Grade II & Grade III & Grade IV & $\mathrm{p}$ Value \\
\hline $\begin{array}{l}\text { Prevalence \% } \\
(n=)\end{array}$ & $\begin{array}{l}61.5 \\
(32)\end{array}$ & $\begin{array}{l}30.8 \\
(16)\end{array}$ & $\begin{array}{l}7.7 \\
(4)\end{array}$ & $\begin{array}{l}0 \\
(0)\end{array}$ & - \\
\hline $\begin{array}{l}\text { Endotracheal intubation } \\
\text { success rate \% } \\
(\mathrm{n}=)\end{array}$ & $\begin{array}{l}87.5 \\
(28 / 32)\end{array}$ & $\begin{array}{l}56.3 \\
(9 / 16)\end{array}$ & $\begin{array}{l}0.0 \\
(0 / 4)\end{array}$ & - & $<0.001$ \\
\hline $\begin{array}{l}\text { Laryngeal mask insertion } \\
\text { success rate \% } \\
(n=)\end{array}$ & $\begin{array}{l}90.6 \% \\
(29 / 32)\end{array}$ & $\begin{array}{l}87.5 \% \\
(14 / 16)\end{array}$ & $\begin{array}{l}75.0 \% \\
(3 / 4)\end{array}$ & - & NS \\
\hline
\end{tabular}

Time to secure the airway is given in table 1 and shown graphically in figure 1. Intubation success was related to laryngoscopic view and results are shown in table 2 .

When laryngeal mask and endotracheal tube insertion were both successful $(n=35$ of 52$)$, there was no significant difference in median time to secure the airway (LM 47.0 seconds (range 24-126) compared with endotracheal tube 52.0 seconds (range 27-148) $\mathrm{p}=0.22$ ). LM insertion was successful in $80.0 \%$ (12 of 15 ) patients in whom endotracheal intubation had failed.

\section{DISCUSSION}

Although several studies have shown the difficulties in prehospital endotracheal intubation, little data exist from the UK. In this study performed in an optimal in-hospital environment, $30 \%$ of paramedic attempts at intubation were unsuccessful. It is probable that performance in the field is less successful. We have also shown that the success rate is related to the view at laryngoscopy. Previous studies have shown that prehospital views of the larynx are less optimal than those in the hospital environment, particularly in the presence of cervical spine immobilisation. ${ }^{27}$ We found that unless at least part of the laryngeal structure was visible, intubation was never successful. This study was performed in patients in whom cervical extension was permitted. In trauma patients where cervical spine immobilisation and manual in-line stabilisation is applied during airway management, the view at laryngoscopy is greatly impaired, with $22 \%$ patients presenting with grade III or IV views with manual in-line stabilisation and $64 \%$ in the presence of a rigid cervical collar. ${ }^{27}$ This is likely to make endotracheal intubation considerably more difficult and the LM airway may be of particular benefit in airway management of patients with cervical spine injuries when cervical spine movement must be minimised..$^{28}$ Although there is evidence that the Mallampati classification also predicts difficulty in laryngeal mask airway insertion, ${ }^{29}$ LM airway insertion is usually possible after failed endotracheal intubation in the hospital setting ${ }^{30}$ and paramedics in this study were also able to secure the airway after failed intubation in $80 \%$ of patients.

The disposable LM was capable of securing the airway successfully. Although there was no statistical difference between the LM and endotracheal tube in time to secure the airway, the comparative data excluded patients in whom endotracheal intubation had failed. Overall, the disposable LM was more successful in securing the airway. Similar success rates have been reported with the LM $(82.1 \%)$ and intubating LM (81.5\%) when inserted by other comparatively inexperienced personnel. ${ }^{31}$ Another smaller hospital based study of USA paramedics and respiratory therapists found the LM easier and quicker to insert, although did not distinguish between the skills of the two professions. ${ }^{26}$ In a manikin study, securing the airway with the LM has previously been shown to be faster when using a standard LM compared with an endotracheal tube when inserted by military medics. ${ }^{32}$ A smaller study of anaesthetists showed that the standard non-disposable LM airway secured the airway more rapidly in patients whose cervical spines are immobilised in a rigid cervical collar when compared with endotracheal intubation. ${ }^{33}$ If the LM is used as an alternative to endotracheal intubation, it is inevitable that paramedics will have less exposure to endotracheal intubation and suffer skill fade as a result. This may result in the need for further training in endotracheal intubation or even consideration as to need to maintain this skill for all paramedics.

Although the overall aspiration rate in patients with major trauma has been reported as high as 34\%, 83\% of these patients aspirated with blood rather than gastric contents, ${ }^{15}$ which is likely to have come from upper airway trauma from which the LM provides good protection. ${ }^{16} \mathrm{~A}$ hospital based study of LM insertion after cardiac arrest also found no evidence of aspiration in any of the 50 patients. ${ }^{14}$

Although endotracheal intubation is often quoted as the "gold standard" in airway management, the significant morbidity associated with this procedure has led to this status being questioned. ${ }^{17}$ The limitation of the LM airway, particularly with regard to airway protection, is perhaps a secondary problem when it is able to consistently secure the airway more rapidly than endotracheal intubation. Hypoxia is likely to be a far larger contributor to morbidity than aspiration of gastric contents.

The introduction of the disposable LM airway has allowed a proven in-hospital airway management device to be made readily available in the prehospital environment. With the known failure rate of prehospital paramedic endotracheal intubation and growing evidence for associated morbidity of this technique, the disposable LM may be an option of growing importance when securing the prehospital airway. The incidence of aspiration after endotracheal intubation and LM airway insertion remains to be determined. Our current knowledge showing a comparatively low incidence of gastric aspiration, ${ }^{15}$ combined with the fact that hypoxia itself is a powerful stimulus to vomiting, may mean that use of a LM airway does not place the airway at as much risk as initially thought. Consideration may also be given to prehospital use of the Proseal LM airway, which may reduce the risks of gastric aspiration further. This variant of the LM airway contains a drainage tube, allowing oesophageal fluid to drain freely and has been shown to be effective in reducing the risk of aspiration of gastric contents, even during active vomiting. ${ }^{34-36}$

The LM may therefore be an airway management device that compares favourably with endotracheal intubation in protecting the airway, while excelling in the primary goal of 
prehospital management-the prompt achievement of tissue oxygenation. Consideration should be given to it being adopted as a standard airway adjunct for paramedics, as it is for emergency department staff, for difficult airway management. Larger studies are needed to investigate the role of the laryngeal mask as the only advanced airway carried by paramedics.

\section{ACKNOWLEDGEMENTS}

We thank paramedics from Hampshire Ambulance Service for participating in this study. We are also grateful to the consultant cardiac anaesthetists and surgeons for allowing us to study their patients.

\section{Authors' affiliations}

C D Deakin, M Cassidy, Hampshire Ambulance Service NHS Trust, Winchester, UK

R Peters, P Tomlinson, Medical School, Southampton University Hospital Trust, Southampton, UK

Conflict of interest: this research was funded by an unrestricted educational grant from Smiths Medical Ltd. CD is a medical advisor to Smiths Medical Ltd.

The results of the initial 44 patients from this study were submitted as an abstract to the 7th Scientific Congress of the European Resuscitation Council, Budapest, September 2004.

\section{REFERENCES}

1 Rocca B, Crosby E, Maloney J, et al. An assessment of paramedic performance during invasive airway management. Prehosp Emerg Care 2000;4:164-7

2 Bradley JS, Billows GL, Olinger ML, et al. Prehospital oral endotracheal intubation by rural basic emergency medical technicians. Ann Emerg Med 1998;32:26-32.

3 Sayre MR, Sakles JC, Mistler AF, et al. Field trial of endotracheal intubation by basic EMTs. Ann Emerg Med 1998;31:228-33.

4 Karch SB, Lewis T, Young S, et al. Field intubation of trauma patients: complications, indications, and outcomes. Am J Emerg Med 1996;14:617-19.

5 Eckstein M, Chan L, Schneir A, et al. Effect of prehospital advanced life support on outcomes of major trauma patients. J Trauma 2000;48:643-8.

6 Murray JA, Demetriades D, Berne TV, et al. Prehospital intubation in patients with severe head injury. J Trauma 2000;49:1065-70.

7 Lockey D, Davies G, Coats T. Survival of trauma patients who have prehospital tracheal intubation without anaesthesia or muscle relaxants: observational study. BMJ 2001;323:141.

8 Mashiko K, Otsuka T, Shimazaki S, et al. An outcome study of out-of-hospital cardiac arrest using the Utstein template-a Japanese experience. Resuscitation 2002;55:241-6.

9 Niemann JT, Stratton SJ, Cruz B, et al. Endotracheal drug administration during out-of-hospital resuscitation: where are the survivors? Resuscitation 2002;53:153-7.

10 Gausche M, Lewis RJ, Stratton SJ, et al. Effect of out-of-hospital pediatric endotracheal intubation on survival and neurologic outcome. A controlled clinical trial. JAMA 2000;283:783-90.

11 Katz S, Falk J. Misplaced endotracheal tubes by paramedics in an urban emergency medical services system. Ann Emerg Med 2001;37:62-4.
12 Dunford JV, Davis DP, Ochs M, et al. Incidence of transient hypoxia and pulse rate reactivity during paramedic rapid sequence intubation. Ann Emerg Med 2003;42:721-8.

13 Joint Royal Colleges Ambulance Liaison Committee. Clinical practice guidelines 2004 (version 3.0). (http://www.nelh-ec.warwick.ac.uk .

14 Kokkinis K. The use of the laryngeal mask airway in CPR. Resuscitation 1994;27:9-12.

15 Lockey DJ, Coats T, Parr MJ. Aspiration in severe trauma: a prospective study. Anaesthesia 1999:54:1097-8.

16 Hobbensiefken G, Savermuller G, Arldt T, et al. Use of the laryngeal mask in oral and dental surgery. Anasthesiol Intensivmed Notfallmed Schmerzther 1988;33:484-8.

17 Nolan JD. Prehospital and resuscitative airway care: should the gold standard be reassessed? Curr Opin Crit Care 2001 7:413-21.

18 Dries DJ, Sample MA. Recent advances in emergency life support. Nurs Clin North Am 2002;37:1-10.

19 Barbieri S, Michieletto E, Di Giulio M, et al. Prehospital airway management with the laryngeal mask airway in polytraumatized patients. Prehosp Emerg Care 2001;5:300-3.

20 Greene MK, Roden R, Hinchley G. The laryngeal mask airway. Two cases of prehospital trauma care. Anaesthesia 1992;47:688-9.

21 Castle N. Use of laryngeal mask airway in pre-hospital environments. Emerg Nurse 2002;10:12-15.

22 Ben-Abraham R, Weinbroum AA. Laryngeal mask airway control versus endotracheal intubation by medical personnel wearing protective gear. Am J Emerg Med 2004;22:24-6.

23 Flaishon R, Sotman A, Ben-Abraham R, et al. Antichemical protective gear prolongs time to successful airway management: a randomized, crossover study in humans. Anesthesiology 2004;100:260-6.

24 Goldik Z, Bornstein J, Eden A, Ben-Abraham R. Airway management by physicians wearing anti-chemical warfare gear: comparison between laryngeal mask airway and endotracheal intubation. Eur J Anaesthesiol 2002;19:166-9.

25 Paech MJ, Lain J, Garrett WR, et al. Randomized evaluation of the single-use SoftSeal and the re-useable LMA Classic laryngeal mask. Anaesth Intensive Care 2004;32:66-72.

26 Reinhart DJ, Simmons G. Comparison of placement of the laryngeal mask airway with endotracheal tube by paramedics and respiratory therapists. Ann Emerg Med 1994;24:260-3.

27 Heath KJ. The effect of laryngoscopy of different cervical spine immobilisation techniques. Anaesthesia 1994;49:843-5.

28 Brain Al. Use of the LMA in the unstable cervical spine. Singapore Med J 2001; Suppl 1:46-8.

29 McCrory CR, Moriarty DC. Laryngeal mask airway positioning is related to Mallampati grading in adults. Anesth Analg 1995;81:1001-4

30 Parmet JL, Colonna-Romano P, Horrow JC, et al. The laryngeal mask airway reliably provides rescue ventilation in cases of unanticipated difficult tracheal intubation along with difficult mask ventilation. Anesth Analg 1998;87:661-5.

31 Burgoyne L, Cyna A. Laryngeal mask vs intubating laryngeal mask: insertion and ventilation by inexperienced resuscitators. Anaesth Intensive Care 2001;29:604-8.

32 Calkins MD, Robinson TD. Combat trauma airway management: endotracheal intubation versus laryngeal mask airway versus combitube use by Navy SEAL and Reconnaissance combat corpsmen. J Trauma 1999:46:927-32.

33 Pennant JH, Pace NA, Gajraj NM. Role of the laryngeal mask airway in the immobile cervical spine. J Clin Anesth 1993;5:226-30.

34 Brimacombe J, Keller C. The ProSeal laryngeal mask airway. Anesthesiol Clin North Am 2002;20:871-91.

35 Keller C, Brimacombe J, Kleinsasser A, et al. Does the ProSeal laryngeal mask airway prevent aspiration of regurgitated fluid? Anesth Analg 2000;91:1017-20.

36 Mark DA. Protection from aspiration with the LMA-ProSeal after vomiting: a case report. Can J Anaesth 2003;50:78-80. 